\title{
TANATOLOGIA FORENSE
}

\author{
José Maria Marlet Pareta \\ Professor Titular do Departamento de Medicina Forense \\ da Faculdade de Direito da Universidade de São Paulo
}

\begin{abstract}
Resumo:
O Autor apresenta os conceitos biológico (processo temporal) e jurídico (instantâneo) de morte, mostrando em que momento os dois coincidem. Mostra, também, a importância de se fazer o diagnóstico da morte o mais precocemente possível, dada a necessidade de se retirar as partes cadavéricas em perfeitas condições para serem devidamente transplantadas. Discute, ainda, os sinais que permitem o diagnóstico precoce da morte, mostrando que nenhum deles é isento de perigos e erros, o que os torna juridicamente muito perigosos.
\end{abstract}

\begin{abstract}
:
The author presents the biologic (temporal process) and the juridical (instantaneous) concepts of death, showing the moment in which the two coincide. It shows, also, the importance of making the diagnosis of the death as early as possible, in view of the need to remove the corpse parts in perfect condition in order to be transplanted

It discusses, also, the sings that allow for an early diagnosis of the death, showing that none of them is exempt of dangers and mistakes, something that makes them juridically very dangerous.
\end{abstract}

"A Tanatologia Forense cuida dos problemas relacionados com a morte naquilo que possa interessar ao Direito" O tema é definido pelo doutor Oswaldo Guilherme Arbenz, saudoso e pranteado professor de Medicina Forense da Faculdade de Medicina da Universidade de São Paulo.

A preocupação básica da Medicina Forense é estabelecer o vínculo entre o fato biológico e as conseqüências jurídicas dele resultantes. Trata-se, em última análise, de uma relação temporal entre causa e efeito, visto que a causa sempre antecede cronologicamente ao efeito.

O conceito de morte está indissoluvelmente ligado ao conceito cronotanatodiagnóstico, que se apresenta na doutrina médico-forense marcado pelo estigma do pessimismo, ligado a Orfila, por atribuir-se a este autor o conceito de que "a cronotanatognose é uma tarefa superior às forças humanas" 
Como se depreende da própria palavra, a cronotanatognose é o conhecimento do tempo transcorrido desde o momento em que ocorreu o êxito letal.

A Medicina Forense está a serviço do Direito e as conceituações do Direito estão freqüentemente ligadas a noções temporais. Isto permite compreender que se deva esperar da Medicina Forense uma função cronodiagnóstica.

Para situar um acontecimento no tempo, precisamos ter um conceito claro do que seja o tempo. Fugindo das conceituações matemáticas ou filosóficas de tempo, aceitaremos a conceituação popular de tempo, isto é, a grandeza que se mede em minutos, horas, dias, meses, anos ou séculos. Embora simplista e empírica, é a única que se nos afigura capaz de contribuir para a solução do problema tanatognósico e, conseqüentemente, o da conceituação de morte.

As categorias temporais do Direito estão sempre no campo da conceituação popular de tempo, justificando-se assim a recusa, anteriormente exposta, de envolver-nos em abstrações matemáticas ou filosóficas a respeito do conceito de tempo.

Não podemos deixar de lembrar, a este respeito, a Zangger quando afirma que datar fenômenos biológicos é uma das tarefas fundamentais e mais difíceis da Biologia.

Os critérios cronológicos não se limitam a classificar os fatos em anteriores ou posteriores; vão mais longe. É preciso medirmos o tempo que separa dois eventos, pois, como afirma com muita certeza Bertrand Russel, só podemos afirmar que conhecemos realmente uma coisa quando somos capazes de medí-la e o conceito de tempo está intimamente ligado ao de medição.

A perícia médico-forense do fato tanatológico está sempre impregnada de fortes conotações cronológicas.

A delimitação cronológica da morte é de relevante valor jurídico, quer em sentido absoluto, bastando lembrar a importância que tem para o Direito o estabelecimento do momento do óbito, como ocorre, por exemplo, nas sucessões, quer em sentido relativo, ao relacionar temporalmente a morte com eventos não ligados diretamente com a mesma, como é o caso, por exemplo, dos problemas ligados à comoriência. 
Os avanços tecnológicos da ciência médica têm feito surgir uma problemática nova, para a qual é de importância crucial o conhecimento do tempo transcorrido desde a ocorrência do êxito letal: é a surgida com a necessidade de retirar partes cadavéricas destinadas a transplante; por isto, a determinação do momento da morte deve ser feita com a máxima precisão e precocidade possíveis a fim de retirar as partes cadavéricas em condições ótimas para serem transplantadas.

Torna-se imperioso, pois, que o médico faça não apenas o diagnóstico do êxito letal, mas também o diagnóstico do momento da morte.

Para estarmos em condições de fixar a cronologia da morte é preciso que estabeleçamos o conceito de morte.

O professor Odon Maranhão ensina que dizer que a morte é a cessação da vida é afirmar um truísmo; que é dizer algo desprovido de sentido, pois não sabemos o que é a vida.

Pese a tão avalizada opinião, preferimos conceituar a morte como a cessação total e permanente das funções vitais, pois não se deve confundir o morrer com a morte aquele é o processo que culmina com esta e, além disto, é assim que a lei o endossa, sem procurar se aprofundar em seus detalhes. Este conceito, tradicionalmente aceito, e que foi considerado por muito tempo como ponto pacífico, teve de ser revisto diante dos modernos processos de transplante de órgãos e tecidos cadavéricos, obrigando a reestudar os conceitos de morte e do momento em que a mesma ocorre.

Da mesma maneira que nos furtamos, por razões pragmáticas de envolvimentos com conceituações abstratas ao tratarmos do tempo, ao conceituar a morte não levaremos em conta as conceituações filosóficas ou religiosas por mais dignas que sejam de respeito; limitar-nos-emos às conceituações embasadas em observações científicas.

Durante muitos anos, acreditou-se que definir a morte era uma redundância, pois "a morte era a morte, e nada mais", como nos lembra o professor Gisbert. Com efeito, o médico era às vezes o último a diagnosticá-la, visto que já antes o tinham feito a família do falecido ou as próprias comadres. Não obstante, o tema, que parecia definitivamente enclausurado, no que diz respeito à sua discussão, converteu-se, de repente, em centro de dúvidas, de 
acaloradas e apaixonadas controvérsias, de polêmicas e discussões sem fim. Esta mudança total teve lugar imediatamente após o primeiro transplante cardíaco.

Se antes deste tinham sido feitos outros tipos de transplante, inicialmente os cutâneos e logo depois os de córnea e ósseos, além de um que outro renal, as peças a serem transplantadas tinham sido retiradas de um corpo já indiscutivelmente morto.

A questão levantada pelo primeiro transplante cardíaco apresentou-se de maneira completamente nova, para não dizer insólita: surgiu da necessidade imperiosa de transplantar a víscera cardíaca em ótimas condições de irrigação e vascularização, o que tornou necessário diagnosticar o mais precocemente possível o momento de ocorrência do êxito letal. Isto obrigou a obter uma certidão de óbito embasada, exclusivamente, na constatação durante um determinado número de horas variável segundo os diversos autores do traçado electrencefalográfico isoelétrico obtido num corpo que, graças a recursos médicos sofisticados, continuava mostrando atividade respiratória e circulatória.

O problema surgiu claramente ao se constatar que o corpo mantido em circulação extracorpórea não é um cadáver. $\mathrm{O}$ cerne do problema reside no fato de que ninguém sabe ao certo se o corpo declarado precocemente cadáver, a pretexto da urgente necessidade de obter vísceras em estado ótimo para transplante, podia, devido às suas reservas energéticas, recuperar-se. Temos visto pacientes fazê-lo após estarem vinte dias em estado de coma profundo.

É claro que os transplantistas buscaram uma solução, não tanto para o problema cirúrgico, quanto ao deontológico. Assim surgiram as chamadas "declarações", como, por exemplo, a de Sydney, porque, no momento atual da ciência médica, o transplante de coração não é um problema cirúrgico, mas uma questão ética.

Sabemos que a morte não é, via de regra, um fenômeno instantâneo, mas antes um processo que se alonga no tempo.

Já D'Hálluin, em 1905, afirmava que a morte processa-se por etapas: "A morte não é a parada total e instantânea da vida, senão um fenômeno lento e progressivo", como aprendemos com Simonin e com Thoinot. No mesmo sentido posiciona-se Veloso França ao afirmar que "a morte se produz por etapas sucessivas, em determinado espaço de tempo, e, por isso, não é ela simplesmente 
um momento ou um instante, como defendem os espiritualistas, mas um verdadeiro processo"

A vida exige a perfeita interligação dos fenômenos biológicos. Com a morte desorganiza-se esta interligação, mas o fluxo de fenômenos biológicos não cessa instantaneamente, qual fluxo elétrico ao acionarmos a chave, antes prolonga-se no tempo com durações variáveis nos diferentes tecidos, até atingir a cessação definitiva. Para Gisbert, a vida equivale a um complexo equilíbrio de fenômenos bioquímicos que seguem leis fixas. Quando há morte, aquelas leis deixam de se cumprir; o corpo fica inerte diante das influências de ordem física, química e microbiana do meio ambiente e inclusive de seu próprio meio interno.

Os diversos tecidos têm potenciais energéticos diferentes, que se esgotam em tempos também diferentes, de maneira que uns tecidos atingem a morte absoluta antes que os outros.

Um dos fenômenos precoces da morte, o da parada cardiocirculatória, não significa necessariamente a morte definitiva. Experiências empíricas e científicas testemunham-no.

A reativação da função cardiocirculatória teve seu primeiro sucesso em 1898 com Tuffier e Hallion, tendo o paciente recuperado inclusive a consciência; logo o paciente, pese a parada cardíaca, não tinha morrido. A partir desta recuperação são incontáveis as reativações da função cardíaca que se têm conseguido até hoje.

Contudo, pese o grande avanço tecnológico representado pelos recursos disponíveis para a manutenção da vida, devemos lembrar Urieta quando afirma que os médicos, às vezes, prolongam a vida de seus pacientes, sem curálos, tolhendo-lhes o direito à ortonasia, isto é, à morte tranquiila.

Por outro lado, tampouco a persistência da função cardiocirculatória significa, obrigatoriamente, a persistência da vida. Hodiernamente dispomos de recursos técnicos capazes de manter artificialmente as funções circulatória e respiratória por longos períodos, o que origina, às vezes, delicados problemas deontológicos.

Não cabe, quando se consegue a reativação da função cardiocirculatória, falar em ressuscitamento. Ressuscitar exige morte prévia e a morte é intrinsecamente irreversível. $O$ paciente, se é potencialmente recuperável, não morreu; encontra-se numa fase pré-mortal, numa fase de 
transição, a que D'Halluin denominou de fase de morte relativa ou morte aparente e Oliveira Sá de fase de vida relativa.

Ponsold ensina que por morte aparente entende-se um estado do organismo no qual os sinais vitais têm-se reduzido a um mínimo tal que dão a impressão errônea de morte.

Tais casos são observados, por exemplo, nas intoxicações graves produzidas por determinados soníferos.

Há indícios que apontam veementemente no sentido de que o estado de morte relativa nada mais é do que o resultado de uma hipoxigenação cerebral.

Quando o estado de morte relativa perdurar durante um tempo prolongado, ocorre a dissociação entre as funções cerebrais e as do resto do corpo, cujos tecidos têm maior resistência que o cérebro à falta de oxigênio.

A existência da fase de morte relativa, que pode faltar em alguns casos, só é provada com o êxito na recuperação das funções vitais. Trata-se de conceito meramente empírico, cujas características íntimas ignoramos. Nem ao menos conhecemos sua duração, pois as recuperações têm variado muito com o tempo de duração, encontrando-se na literatura citações que falam em recuperações obtidas após cento e quarenta minutos, embora seja hábito fixar o tempo possível de recuperação em dez minutos.

Alguns autores, como por exemplo Lhermitte, negam que a recuperação da função cardiocirculatória seja uma revivescência, se as funções cerebrais superiores não forem também recuperadas. Não endossamos esta opinião, pois, de aceitá-la, deveríamos negar a qualidade de vivo ao paciente em estado de coma profundo, contrariando a própria lei, que lhe garante o estado de pessoa, e, como tal, sujeito de direitos legalmente amparados.

Esta fase pode inexistir ainda na presença de funcionamento cardíaco. A História lembra o caso de um homem guilhotinado, cujo coração continuou a bater quase meia hora depois da decapitação.

Se ao suspendermos os meios de manutenção artificial das funções vitais básicas, as mesmas não continuam espontaneamente, podemos afirmar que a fase de morte relativa foi superada. Neste sentido manifestaram-se numerosos especialistas, inclusive algumas encíclicas papais, como, por exemplo, a de Pio XII. 
Frache é de opinião que a morte histológica é mais o resultado dos catabolitos que se acumulam do que dos anabolitos que não chegam; logo a superação da fase de morte relativa acontece quando a intoxicação catabólica torna-se intolerável.

Autores soviéticos, como Shuster, Gaevskaya e Petrov, mostraram a existência de alterações bioquímicas cerebrais durante a fase de morte relativa, as quais, ao ultrapassarem certos limites, definem o fim da mesma, ao perder o cérebro a capacidade de responder às manobras revivescentes, com o que se alcança o início da próxima fase, a de morte intermédia, caracterizada pela irreversibilidade do processo, com permanência da vida residual em níveis meramente histológicos. As reações biológicas ocorridas nesta fase recebem o nome de supravitais ou transvitais.

Como exemplos clássicos de vida residual próprios da morte intermédia, podemos lembrar a sobrevivência dos espermatozóides e dos leucócitos.

Têm-se destacado no estudo da fase de morte intermédia os autores italianos e japoneses, em especial, dentre outros, Wada, Astalti, Forti e Sacchetti, que deram ênfase à sobrevida das células hemocitopoiéticas da medula óssea.

$\mathrm{O}$ fato de os fenômenos de vida residual terem durações desiguais, por serem desiguais suas capacidades energéticas, como já dissemos, faz com que uns acabem antes dos outros, de maneira a coexistirem simultaneamente áreas em fase de morte intermédia e áreas em fase de morte absoluta, como já tinha assinalado Lacassagne ao afirmar que o corpo não morre todo ao mesmo tempo.

Diante das dificuldades que a parada cardiocirculatória apresentava como definidora do momento da morte, passou-se a avaliar, com esta finalidade, a parada do funcionamento cerebral. Já Urieta afirmava, em 1883, que a morte cerebral, isto é, a irreversível perda de todas as funções cerebrais, podia ser reconhecida como base para se declarar a pessoa morta.

O critério de morte cerebral é baseado na extinção da atividade elétrica do cérebro, tanto do córtex como das estruturas mais profundas. Porém, a interpretação do traçado electrencefalográfico criou algumas controvérsias, pois é sabido que os electrencefalógrafos usados na clínica só captam a energia 
elétrica das zonas periféricas do cérebro, ignorando o que acontece na intimidade do mesmo.

Humphry e Wickett lembram no livro $O$ direito de morrer, publicado em 1989, que o cérebro morre por etapas começando pelo córtex.

Um traçado electrencefalográfico isoelétrico é indício de morte somente quando persistente. Não obstante, as intoxicações barbitúricas graves têm demonstrado que o traçado electrencefalográfico isoelétrico pode persistir durante horas ou ainda dias, sem que se perca necessariamente a possibilidade de recuperação. O British Medical Journal apresentou, em 1968, cinco exemplos de recuperação de intoxicados com prolongados traçados isoelétricos.

Kimura, por sua vez, afirma que não é fácil, diante de um traçado electrencefalográfico isoelétrico, determinar o tempo necessário para se afirmar a realidade do óbito. Na sua casuística tem vinte e cinco casos de pacientes com traçados isoelétricos, com circulação e respiração controladas, cuja morte demorou de um a quinze dias, sendo que dois dos pacientes recuperaram-se.

Também nas clínicas neurológicas brasileiras há experiência a este respeito. O Jornal da Associação Médica Brasileira, de outubro de 1991, publicou um artigo em que se narra a recuperação de dois pacientes, após prolongado silêncio electrencefalográfico.

A Sociedade Alemã de Cirurgia exige, para se afirmar a realidade da morte, um mínimo de doze horas de inconsciência, sem respiração espontânea, midríase bilateral e traçado electrencefalográfico isoelétrico, ou que o angiograma revele cessação de circulação intracraniana durante no mínimo trinta minutos.

Simpson, professor de Medicina Legal de Londres, afirmou recentemente que jamais autorizaria a retirada de um órgão num enfermo mantido com respiração e circulação controladas, qualquer que fosse o traçado electrencefalográfico.

Em 1967, Breecher, em palestra proferida na Faculdade de Medicina de Harvard, alertou para o fato de que o desejo de aceitar os critérios de lesão cerebral irreversível para formular uma nova conceituação de morte, procede de certos interesses criados. E, entre os mesmos, citou os das familias que desejam acabar com uma interminável agonia; os dos cirurgiões, interessados em dispor de órgãos cadavéricos em ótimas condições para 
transplante; e os da sociedade em geral, alarmada diante dos elevados gastos de assistência nos casos considerados irrecuperáveis.

Dificilmente alguém aprovaria

querida, enquanto estiverem em funcionamento, mesmo que assistidas por recursos mecânicos, a respiração e a circulação, qualquer que fosse seu traçado electrencefalográfico.

Se se aceita que o simples traçado electrencefalográfico isoelétrico não equivale à morte certa, fortes objeções deontológicas se levantam diante do fato de manter estes corpos com circulação e respiração controladas, a fim de os transformar em verdadeiros bancos de órgãos.

$\mathrm{O}$ dito justifica que o médico não deva se basear em apenas um critério para decidir se já ocorreu o êxito letal, sendo necessário e indispensável, para fazê-lo, recorrer a um rigoroso raciocínio clínico.

Wertheimer e Jouvet foram os primeiros a propor uma definição de morte cerebral baseada simultaneamente em critérios clínicos e electrencefalográfico.

O conceito de morte cerebral é pouco simpático à sociedade em geral. Não podemos ignorar o fato de sermos um povo de cultura eminentemente cardiólatra, que localiza inclusive no coração a sede de nossos sentimentos. Por isto, se vivemos pelo coração, igualmente por ele queremos morrer. Isto se traduz na prática pelo fato de que mais de $95 \%$ dos óbitos são diagnosticados pela parada cardiorrespiratória.

Contudo, não resta dúvida que são as condições cerebrais, como um todo, as que comandam o término da morte relativa.

Embora a morte seja um processo que se prolonga no tempo, para fins forenses é preciso atribuir-lhe um momento, fixar-lhe uma data, torná-la cronologicamente útil. $\mathrm{O}$ Direito, ao considerar o momento da morte como o momento em que desaparece a pessoa física como ente jurídico, o momento em que se extinguem direitos e obrigações, o momento em que a pessoa física passa à categoria de cadáver, obriga a Medicina a identificar um momento, dentro do processo mortal, ao qual possamos nos referir como "momento da morte"

A dificuldade é aparentemente enorme, pois o médico deve identificar o conceito jurídico de morte (que é instantâneo) ao conceito biológico (que é um processo temporal). 
O que interessa, do ponto de vista jurídico, é o estabelecimento do momento em que ocorre a extinção da personalidade jurídica da pessoa física e cabe ao médico determinar quando isto ocorre, fazendo-o, habitualmente, quando no atestado de óbito data e fixa a hora do êxito letal.

O problema restringe-se, na realidade, à determinação da transição da fase de morte relativa (potencialmente reversível) para a fase de morte intermédia (já irreversível). Neste sentido posicionou-se o Congresso Mundial de Médicos, reunido na Austrália em 1968, de que resultou a famosa Declaraçāo de Sydney, onde se afirma que o momento da morte das diferentes células do organismo é menos importante do que a certeza da irreversibilidade do processo letal.

Não temos dúvida de que a equivalência entre os dois conceitos de morte, o jurídico e o biológico, ocorre no momento da transição para a fase de morte intermédia, por ser o momento em que se inicia a irreversibilidade do processo letal, embora haja vozes autorizadas, como as de De Vicentiis e de Cuttica, que não aceitam isto. Com eles não concordamos, pois se a decretação legal da morte acontecesse durante a fase de morte relativa e, após esta declaração, ocorresse a revivescência, seria necessário admitir que, tendo-se extinguido a personalidade jurídica da pessoa física por força daquela decretação, a revivescência criaria o paradoxo de exigir nova personalidade jurídica, com as terríveis complicações legais que disto adviriam, como abrir possibilidade de casar com a própria viúva ou da perda do patrimônio em favor dos herdeiros, para dar apenas alguns exemplos. Para evitá-lo, a morte legal deve ser fixada no momento em que o processo letal torna-se irreversível, isto é, na transição da fase de morte relativa para a fase de morte intermédia.

A própria etimologia da palavra cadáver nos ajuda nesta empreitada. $\mathrm{O}$ vocábulo cadáver origina-se de cado, que significa cair, sumir, e daí o termo cadáver significando o sumir da vida.

A conceituação legal de morte ou morte clínica, como é freqüentemente chamada, implica que a pessoa física deixa de existir como unidade social, pouco importando se em seu corpo ainda existem formas residuais de vida. Esta foi a posição adotada pela Declaração de Sydney, ao afirmar que o interesse clínico não reside na manutenção da vida de células 
isoladas, senão da pessoa. Concordamos plenamente com esta colocação do problema letal.

Discutido o conceito de morte, passemos à conceituação de sua cronologia.

A cronotanatognose é feita pelo estudo das evoluçôes dos livores, do resfriamento, da rigidez, dos fenômenos transformativos e das alterações bioquímicas. Pode ser complementada pelo estudo dos fenômenos locais, como o da desidratação ocular ou o estado digestivo dos alimentos encontrados no estômago do cadáver quando se conhece a hora da última refeição.

Os livores, devido à sua natureza puramente mecânica, são pouco influenciados pelos fatores ambientais, tais como umidade e temperatura, embora sejam muito sensíveis às espoliações hemáticas pré-mortais.

$\mathrm{O}$ estabelecimento do início dos mesmos varia muito segundo os autores. Enquanto Ponsold o estabelece em quinze minutos após a morte, Kockel acredita que se iniciam após doze horas. Encontramos as mesmas divergências em relação ao momento em que os mesmos tornam-se fixos, pois enquanto alguns autores os consideram definitivamente fixados após três horas, outros alongam este tempo para quinze horas.

O resfriamento, por ser fenômeno puramente físico, está extremamente influenciado pelas condições ambientais. Cessadas com a morte as funções metabólicas, tão necessárias à manutenção da homeotermia indispensável à vida, o cadáver fica sujeito à primeira lei da termodinâmica, que afirma que quando dois corpos, de temperaturas diferentes, se encontram, o mais quente cede calor ao mais frio até as temperaturas se igualarem. É óbvio que a temperatura diferencial entre o cadáver e o ar é fundamental. Quanto maior for a mesma, mais rápida será a troca de calor e mais rápido o resfriamento do cadáver. Por isto, se o cadáver estiver num ambiente extremamente quente, será o ar quem cederá calor e o mesmo, ao invés de resfriar, aquecer-se-á. Isto prova a inutilidade das tabelas destinadas a avaliar o tempo transcorrido desde o êxito letal, partindo da temperatura cadavérica. A complicar mais a coisa, milita o fato de que as condições internas também têm influência na velocidade do resfriamento do cadáver. Mueller provou, recentemente, que os cadáveres com panículo adiposo abundante demoram mais em resfriar que os cadáveres magros. 
A rigidez, sendo um fenômeno essencialmente bioquímico, também é influenciada fortemente pelas condições climáticas basta lembrar que o calor a encurta e o frio a prolonga -, as discrepâncias cronodiagnósticas entre os autores são grandes. Enquanto que para uns começa aos trinta minutos do óbito, generalizando-se em três horas, para outros começa às duas horas, completandose com doze horas. Seu relaxamento sói acontecer, para a maioria dos autores, no segundo ou terceiro dias, embora Morgenstern informa ter encontrado relaxamento entre sete e vinte horas de cadáveres mantidos a trinta graus centígrados e outros, mantidos na geladeira, que a conservaram até doze dias.

A evolução das transformações cadavéricas ainda é de valor cronodiagnóstico menor. Orfila, após exumar centenas de cadáveres, não conseguiu descobrir características cronodiagnósticas na putrefação cadavérica.

O mesmo cabe dizer do estudo da flora e fauna cadavéricas, exaustivamente estudadas por Leclerc e por Coutelen.

As pesquisas experimentais não nos ajudaram em nada, pois as condições em que se processam os fenômenos transformativos são tão polimorfas, que não há possibilidade de as reproduzir experimentalmente.

Alguns autores chegaram a propor complicadas equações matemáticas incluindo diversas das variáveis estudadas; com elas conseguem-se estimativas cronológicas mais confiáveis que quando se consideram as variáveis isoladamente, sem, contudo, conseguir resolver o problema do estabelecimento correto do cronodiagnóstico.

Tem-se aberto promissoras perspectivas cronodiagnósticas com o recentíssimo estudo das alteraçôes bioquímicas no sangue e no líquido cefalorraquiano, que tem se mostrado praticamente constantes na sua evolução, mas de velocidades de ocorrência ainda pouco conhecidas ou o abaixamento do pH sangüíneo, estudado recentemente por Akiya.

Após a revisão do valor cronodiagnóstico dos fenômenos cadavéricos globais, passemos em rápida revista os fenômenos localizados.

Dentre eles, merecem especial atenção os fenômenos oculares, cujo estudo começou em princípios do século com Corin, mais tarde continuados por Kekorkian, que estudou as alterações retinianas. Entre nós, tem-se ocupado deste estudo Canger Rodrigues, que estudou a velocidade de desidratação da 
câmara anterior do olho e eu, que a estudei na câmara posterior, por ser menos influenciada pelas condições ambientais.

Ponsold, por sua vez, sugere o estudo da evolução das diferenças de hemoconcentrações entre o coração direito e o esquerdo.

Todos estes estudos mostraram-se, infelizmente, de pouco valor na estimativa do tempo transcorrido desde a ocorrência do êxito letal.

Devido, provavelmente, às dificuldades encontradas, os pesquisadores têm se desinteressado pelos estudos cronotanatodiagnósticos, dando razão a Orfila, quando o mesmo as considera tarefas acima das forças humanas.

Contudo, observa-se um início de reação a este desinteresse, provavelmente estimulado pela necessidade de partes cadavéricas para transplante. Por exemplo, Romero Palanco publicou no último número da Revista Espanhola de Medicina Legal interessante estudo mostrando ser possível a aplicação da ultra-sonografia aos estudos cronotanatodiagnósticos.

Felizmente, quanto mais recentes são as observações e as medições, tanto mais fidedignas se tornam as estimativas cronodiagnósticas, cuja margem de erro aumenta à medida que o cadáver envelhece e para a retirada de partes cadavéricas para transplante as estimativas devem ser muito precoces.

Resumindo, a Tanatologia Forense ocupa-se dos problemas relacionados com a morte naquilo que possa interessar ao Direito, como nos ensinou o professor Arbenz; e os dois principais temas que interessam neste campo são o conceito de morte e o da avaliação do tempo transcorrido desde a ocorrência do óbito.

Em relação ao primeiro, vimos que o conceito biológico de morte é o de um processo que se prolonga no tempo, no qual é possível diferenciar algumas etapas: a primeira é a de morte relativa, ainda passível de reversibilidade, cujas características desconhecemos, inclusive ignoramos sua duração; a segunda é a de morte intermédia, caracterizada pela irreversibilidade do processo letal e a permanência de formas residuais de vida em nível meramente histológico; a terceira é representada pela morte absoluta na qual, tendo-se esgotado os potenciais energéticos responsáveis pelos fenômenos supravitais, desaparece qualquer forma de vida. 
Não dispomos de um único sinal seguro de morte, suficientemente precoce, para atender às modernas exigências impostas pela necessidade de retirar órgãos cadavéricos destinados a transplante.

Vimos que a parada cardíaca não significa forçosamente a ocorrência de êxito letal e nem a persistência dos batimentos cardíacos representam sempre a existência de vida.

Vimos, igualmente, que o traçado electrencefalográfico isoelétrico nem sempre equivale à morte cerebral.

Por outro lado, o conceito jurídico de morte exige que o diagnóstico da mesma seja instantâneo e que cabe à Medicina Forense estabelecer a coincidência dos dois conceitos de morte, o biológico e o jurídico, estabelecendo-a na transição da fase de morte relativa para a de morte intermédia, por ser o momento em que o processo letal torna-se irreversível.

Vimos, ainda, que os estudos científicos destinados a descobrir recursos que permitam uma avaliação cronotanatológica confiável são poucos e que se encontram ainda em estado incipiente.

Podemos afirmar, para concluir, que no estágio atual de nossos conhecimentos, os esforços despendidos para conceituar a morte e estimar o tempo transcorrido desde a mesma, são desejáveis para a Medicina, porém juridicamente perigosos. 